\title{
Rasgos identitarios del discurso de la movilización Minga de Resistencia Social y Comunitaria $^{1}$
}

\author{
DOI: https://doi.org/ 10.25100/hye.v16i54.9919
}

Artículo recibido: 08-10-2018 Artículo aceptado: 17-02-2019

\section{William Bermeo Dagua}

Licenciado en Filosofía graduado de la Universidad del Valle, cuenta con una maestría en Lingüística y Español en la Universidad del Valle y es Doctor en Humanidades por la misma institución. Actualmente es profesor asistente del Departamento de Lingüística y Filología de la Universidad del Valle.

Universidad del Valle, Colombia.

Correo electrónico:William.bermeo@correounivalle.edu.co

ORCID: 0000-0002-7909-4374

Forma de citar este artículo: Dagua, William Bermeo. "Rasgos identitarios del discurso de la movilización Minga de Resistencia Social y Comunitaria" Historia y Espacio, vol. 16 n 54 (2020): 237-264. Doi.org/ 10.25100/hye.v16i54.9919

Artículo Tipo 2: de reflexión. 1Este artículo de investigación deriva de la tesis doctoral El discurso de la movilización Minga de Resistencia Social y Comunitaria. Un discurso político de resistencia, presentada por el autor en el año 2018 en el Doctorado en Humanidades de la Universidad del Valle. 


\section{Resumen}

En este artículo se presentan los resultados de una investigación que analizó el discurso dela movilización denominada Minga de Resistencia Socialy Comunitaria. Un objetivo del estudio, puesto de manifiesto este trabajo, apuntó a identificar y explicar tanto los rasgos contextuales como los de contenido que caracterizan dicho discurso. La investigación fue de carácter cualitativo y de tipo exploratorio e hizo el análisis discursivo de una muestra constituida por 41 documentos, a partir de conceptos y categorías tomadas de los estudios del discurso, pero también con base en otros recuperados de las ciencias sociales. Como técnica de análisis se empleó el análisis de contenido. Respecto al primer tipo de rasgos se encontró que este discurso instituye el género discursivo comunicación política de resistencia, siendo su principal característica la hibridez. Respecto al segundo, se halló que las representaciones sociales expresadas guardan correspondencia con una ideología antineoliberal. Por cuanto solo se examinaron los rasgos específicos de un discurso sociohistóricamente situado, se concluye que dichas características no pueden hacerse coextensivas a cualquier discurso de resistencia en general.

Palabras clave: género discursivo, discurso político de resistencia, rasgos contextuales, rasgos de contenido, análisis de contenido, ideología antineoliberal.

\section{Abstract}

This article presents the results obtained in a research that analyzed the discourse used in a mobilization called the Mobilization Minga of Social and Communitarian Resistance. This work aims to identify and explain the contextual and content features inherent in this discourse. This qualitative and exploratory research carried out an analytical analysis of a 41-document sample. The analysis was based on concepts and categories taken not only from discourse studies, but also on other recovered categories and concepts from social sciences. The content analysis was the technique used in this work. For contextual features, it was found out that this discourse involves the discourse genre of political resistance communication, having a hybrid characteristic. With respect to content features, it was found out that the expressed social representations correspond to the anti-neoliberal ideology. Due to the fact that only the specific features of a social discourse in a historical time were examined, it can be concluded that, in general, these features cannot be coextensive to any resistance discourse.

Keywords: discourse genre, political resistance discourse, contextual features, content features, content analysis, anti-neoliberal ideology. 


\section{William Bermeo Dagua}

\section{Rasgos identitarios del discurso de la movilización Minga de Resistencia Social y Comunitaria}

\section{Introducción}

Como práctica social de sujetos colectivos contra el poder, la resistencia civil es tan antigua como el poder mismo. En tanto que acción colectiva de sujetos colectivos, independiente de las formas que haya adoptado, la resistencia no es un asunto nuevo. Resistencias ha conocido el mundo antiguo, el medieval, el moderno y el contemporáneo. Acierta Jaime R. Nieto cuando señala que resistencias "ha conocido el mundo americano prehispánico, conquistado, colonizado"2 . Es más, resistencias sigue conociendo el mundo en general. Por supuesto, América Latina no ha escapado a ello, y Colombia tampoco.

Colombia es una nación en la que la dinámica y las características del poder hegemónico del capitalismo mundial se han conjugado de manera integral. Como bien apunta Jaime R. Nieto, uno de los ejes de este poder ha sido la continuidad, la consolidación y la intensificación hegemónica de la globalización neoliberal de la economía impuesta por los países del capitalismo metropolitano sobre los países periféricos, a través de las ya conocidas instituciones financieras transnacionales como el Fondo Monetario Internacional y el Banco Mundial, en asocio con las clases dominantes nativas ${ }^{3}$.

Sin embargo, es claro que para el caso de Colombia este poder dominante, sintetizado bajo el epíteto de neoliberalismo armado, ha tenido aplicaciones y desarrollos concretos, pues, en efecto, cada país responde a condiciones sociohistóricas que le son particulares.

En palabras de Libardo Sarmiento, es desde finales de la década de los ochenta que en Colombia se empezaron a promover políticas económicas de corte neoliberal, y continuadas, a su vez, por los gobiernos de turno sin excepción alguna ${ }^{4}$. Esto significa que gobiernos como los de Álvaro Uribe, en sus dos periodos

2 Jaime Rafael Nieto, Resistencia. Capturas y fugas del poder (Bogotá: Ediciones Desde Abajo, 2008), 37.

3 Nieto, Resistencia. Capturas y fugas, 29.

4 Libardo Sarmiento Anzola, "Terrorismo neoliberal. Balance social desde los noventa”, Traza, n. ${ }^{\circ} 1(2002): 39$. 
(2002-2006 y 2006-2010), también se inscribieron en esta directriz, tanto más cuanto la negociación del Tratado de Libre Comercio (TLC) con los Estados Unidos confirmó el interés del gobierno Uribe por consolidar el modelo neoliberal. Incluso este mandatario mantuvo una alianza incondicional con la política internacional contra el terrorismo, el otro eje del poder hegemónico mundial, ya que la política de seguridad democrática, su programa bandera, sintetizó esa política gubernamental de guerra contra el terrorismo. Es más, el presidente Uribe reconceptualizó la visión que se tenía de conflicto armado interno en Colombia. Con él, el conflicto dejó de ser definido en términos de política nacional y pasó a ser tratado en términos de política internacional. Uribe sostuvo y sigue sosteniendo como senador de la república que lo que Colombia enfrenta son amenazas y ataques terroristas contra las instituciones democráticas.

Estas políticas gubernamentales de corte neoliberal que el presidente Uribe comenzó a implantar desde el inicio de su primer mandato, sumadas a las medidas con que enfrentó el conflicto armado interno desde la perspectiva de la guerra global contra el terrorismo, de una u otra manera incidieron en las políticas sociales y económicas del país. Sin embargo, esta conjunción de medidas y políticas no se impuso sin acciones colectivas de resistencia civil ${ }^{5}$.

Es así como en el año de 2008, distintos sectores y organizaciones sociales de Colombia (indígenas, afrodescendientes, campesinos, trabajadores en general y otros sectores sociales urbanos) decidieron construir desde abajo una movilización popular conjunta, la que se conoce con el nombre de Minga ${ }^{6}$ de Resistencia Social y Comunitaria (MRSC). Se trató de un acontecimiento sociopolítico gestado en el norte del departamento del Cauca y llevado a

5 De acuerdo con Michael Randle, la resistencia civil es un método de lucha política colectiva que procura desafiar la autoridad y la legitimidad del gobierno y privarlo de esa manera de su fuente de poder residente en la colaboración de las instituciones de la sociedad y del estado. Michael Randle, Resistencia civil (Buenos Aires, Editorial Paidós, 1998), 114.

6 "Minga es una práctica ancestral de los pueblos indígenas de los Andes. Es un esfuerzo colectivo convocado para lograr un objetivo común. Cuando se convoca una minga ésta tiene prioridad sobre otras actividades, que se posponen para cumplir con el propósito común. Los resultados de la minga no tienen dueños. Los logros son del colectivo y nadie de manera particular puede apropiárselos. Las mingas ponen en evidencia la madurez de los pueblos. La disciplina, la capacidad de actuar en comunidad, la humildad, el aporte del esfuerzo individual máximo para un logro colectivo, la conciencia de que lo común supera lo particular, pero que cada esfuerzo particular es esencial, constituyen elementos que ponen en evidencia la cualidad ejemplar y ejemplarizante de la minga”. Consultado en: http://www. nasaacin.org. 
cabo entre los meses de octubre y noviembre de 2008, durante el segundo mandato de Álvaro Uribe (2006-2010). Fue promovido por las principales organizaciones indígenas de Colombia, entre ellas, la Asociación de Cabildos del Norte del Cauca ${ }^{7}(\mathrm{ACIN})$, principal promotora de la minga, respetada por su liderazgo, por defender sus planes de vida y gozar de reconocimiento nacional e internacional.

En aras de destacar el rol que en el desarrollo de la MRSC jugó la ACIN, valga señalar que una de las redes organizativas que hacen parte de su estructura, el Tejido de comunicaciones y relaciones externas para la verdad y la vida siempre acompañó las acciones materiales de esta protesta con conjunto de producciones verbales y escritas, divulgadas a través de la página web www.nasaacin.org. Entre las características de estas producciones se observó: primero, que expresan un determinado posicionamiento en un campo discursivo específico, esto es, que conciernen a producción discursiva de ciertos contenidos (creencias y actitudes ideológicas, imaginarios sociodiscursivos, marcos de acción colectiva,); $y$, segundo, que testimonian distintas dimensiones del discurso (uso de géneros discursivos específicos, ciertas estrategias discursivas, determinadas estructuras del discurso). El hecho de que estos textos compartieran unos rasgos comunes condujo a acuñar la expresión $e l$ discurso de la movilización MRSC.

Sin embargo, como este discurso apuntó a dar cuenta del proceso de oposición y resistencia que las organizaciones participantes emprendieron en contra de las políticas gubernamentales, globalizadoras y neoliberales, implementadas por Uribe Vélez, se propuso, entonces, que dicha movilización constituía una forma de hacer oposición política. Esta determinación fue producto de recuperar el concepto de oposición dado por Norberto Bobbio y Nicola Matteuci, quienes lo definen como:

7 La Asociación de Cabildos Indígenas del Norte del Cauca (ACIN) se creó en el año de 1994. Junto con otras asociaciones de cabildos conforman el Consejo Regional Indígena del Cauca (CRIC), que a su vez hace parte de la Organización Nacional Indígena de Colombia (ONIC). La ACIN tiene su sede en el municipio de Santander de Quilichao, norte del departamento del Cauca. Agrupa 14 resguardos y 16 cabildos indígenas, distribuidos en 7 municipios. Esta asociación indígena es la más reconocida del país, no sólo por su liderazgo y por defender sus planes de vida, sino también por su resistencia pacífica tanto al conflicto armado como a la agresión neoliberal. Incluso en el ámbito internacional la ACIN es más conocida que la propia Organización Nacional Indígena (ONIC) y que el mismo Concejo Regional Indígena del Cauca (CRIC). Consultado en: http: //www.nasaacin.org 
La unión de personas o grupos que persiguen fines contrapuestos a aquellos individualizados y perseguidos por el grupo o por los grupos que detentan el poder económico o político o que institucionalmente se reconocen como autoridades políticas, económicas y sociales respecto de los cuales los grupos de oposición hacen resistencia sirviéndose de métodos y medios constitucionales legalistas o ilegales y violentos ${ }^{8}$.

Observar este concepto de oposición desde el terreno de los estudios del discurso fue importante porque permitió proponer que todos estos textos producidos por la movilización MRSC constituyeron una novedosa práctica social, con las implicaciones que ello supone, de hacer resistencia discursiva, entendiendo por ello la práctica sociodiscursiva a la que un grupo de contrapoder puede acudir para hacer oposición política mediante la expresión de discursos, en géneros discursivos ${ }^{9}$ específicos, tendientes a evidenciar, denunciar y deslegitimar políticas y medidas gubernamentales que vulneran o amenazan con vulnerar sus derechos fundamentales.

En efecto, es sabido que, así como las instancias que detentan o ejercen el poder, independientemente de la concepción que se tenga de este, suelen acudir al discurso para legitimar su ejercicio o para construir un consenso o el consentimiento a su dominación; de igual modo, los grupos dominados han encontrado que cuando tienen acceso a aquel, por lo menos en un régimen democrático, también lo pueden emplear para ejercer su derecho a la resistencia civil. Por lo tanto, del hecho de decir que el discurso de la movilización MRSC respondió a un discurso encaminado a hacer resistencia pacífica a aquellos aspectos de la realidad política del momento y respecto de los cuales las organizaciones sociales discrepaban, se desprende que tal discurso es por lo mismo como un discurso político de resistencia, ya que en esencia constituyó un discurso de denuncia, cuestionamiento y resistencia a las políticas públicas neoliberales implementadas por el gobierno de Uribe Vélez.

8 Este concepto es citado por Luisa F. Trujillo, "Resistencia civil en el Cauca como forma de oposición”, en Renovadas formas de hacer oposición, compilado por Fredy Cante y Beatriz Franco (Bogotá D. C: Editorial Universidad del Rosario, 2014), 203.

9 Desde una perspectiva sociocomunicativa, para Patrick Charaudeau los géneros discursivos se determinan a partir de los diferentes ámbitos de la práctica social que se instauran en una sociedad; el propósito es observar cómo las prácticas lingüísticas se vinculan con ellos. Patrick Charaudeau, "Los géneros: una perspectiva sociocomunicativa”, en Los géneros discursivos desde múltiples perspectivas: teorías y análisis, editado por Martha Shiro, Patrick Charaudeau y Luisa Granato (Madrid: Editorial Iberoamericana, 2012), 28. 
En síntesis, aunque esta movilización constituyó un momento de un proceso de minga, constante y dinámico de resistencia, que viene desde antes, pero que aún no deja de manifestarse, no obstante lo que también se puede sostener es que, a pesar de que en las comunidades indígenas colombianas la palabra minga sigue manteniendo su significado original de trabajo ancestral colectivo, convocado para alcanzar objetivos comunes, ahora dicha práctica social y tales objetivos no están relacionados únicamente con suplir necesidades materiales, cultivar, cosechar, construir, sino que son elevados a otro nivel de praxis sociodiscursiva: hacer minga discursiva para resistir discursivamente.

De allí que el presente artículo se encamine dar cuenta del discurso político de resistencia de la movilización MRSC con el propósito de determinar y explicar sus principales rasgos.

\section{Metodología}

La investigación realizada fue de carácter cualitativo y de tipo exploratorio e involucró las siguientes orientaciones epistemológicas: la perspectiva semiodiscursiva ${ }^{10}$, el enfoque sociocognitivo del discurso y el enfoque análisis del discurso político. Este artículo se fundamenta en la primera perspectiva por cuanto constituyó el horizonte teórico desde el cual se definieron las categorías de análisis que permitieron dar cuenta de los rasgos distintivos del discurso la movilización MRSC.

La población objeto de estudio comprendió 92 documentos escritos, publicados en el portal electrónico www.nasaacin.org, página web de la Acin, entre octubre 11 y noviembre 21 de 2008. A partir de un muestreo no probabilístico, por conveniencia, se seleccionaron 41 documentos que, por sus características comunes, constituyeron lo que se denomina el discurso político de resistencia de la movilización MRSC. La selección de la muestra se hizo con base en los criterios de inclusión y de exclusión que se describen a continuación.

${ }^{10}$ Desde esta perspectiva se recogieron los aportes de Patrick Charaudeau, quien señala que todo acto de comunicación puede definirse como un acto de intercambio siempre interactivo en el que el sentido que resulta de dicho intercambio no sólo depende de la intención del hablante, sino también de la del sujeto que interpreta. En efecto, todo acto de lenguaje es un acto cointencional en el que se co-construye sentido, tanto más cuanto de lo que se trata es de abordar de manera conjunta el fenómeno de representación de las palabras y el de su fuerza de influencia. Patrick Charaudeau, "Semiolingüística y comunicación”, Núcleo-4, 29 (UCV, Caracas, 1986): 6. 
Como criterio de inclusión se consideraron todos aquellos textos que tuvieron como locutor responsable a sujetos colectivos que hicieron parte de la movilización MRSC. El contenido de estos documentos involucró la totalidad o algunos de los siguientes cinco temas: no aceptamos tratados de libre comercio; denunciamos, resistimos y exigimos la derogatoria de las reformas constitucionales y de la legislación del despojo; no más terror a través del plan Colombia, la seguridad democrática, la parapolítica; exigimos el cumplimiento de acuerdos, normas y convenios que se ignoran de manera sistemática; construyamos la agenda de los pueblos: de un país con dueños y sin pueblos a un país de los pueblos sin dueños; temas fundamentales que guiaron la movilización.

Como criterio de exclusión se descartaron aquellos textos que, si bien fueron divulgados por el Tejido de comunicación de la Acin, fueron producidos por sujetos individuales o colectivos que no participaron de la movilización.

Una vez constituida la muestra, los textos fueron guardados en el programa de análisis de datos cualitativos Atlas TI. Luego se procedió a su análisis aplicando como técnica el análisis de contenido, en su versión más reciente. Esta versión, en palabras de Cecilia Minayo:

busca alcanzar un nivel más profundo, toda vez que sus procedimientos apuntan a relacionar estructuras semánticas con estructuras sociológicas, a la vez que articula la superficie de los enunciados de los textos con los factores que determinan sus características: variables sicosociales, contexto cultural y condiciones de producción ${ }^{11}$.

\section{Esta técnica de análisis involucró tres fases:}

Pre-análisis: los documentos fueron organizados de acuerdo con su autor. Posteriormente se muestra el énfasis que se le dio a cada uno de los siguientes cinco puntos que constituyeron las razones de la movilización MRSC. Exploración del material: se presenta el instrumento de análisis diseñado para cada enfoque teórico y se describen las categorías y códigos considerados para el análisis analítico. Para el asunto puntual de la definición de los rasgos contextuales y de contenido del discurso de la MRSC, se hizo tomando como referencia la perspectiva semiolingüística desarrollada por Patrick Charaudeau

${ }^{11}$ Cecilia Minayo, El desafío dl conocimiento. Investigación cualitativa en salud (Buenos Aires: Lugar,2004), 198. 
(1983, 1986, 1992, 2005a, 205b, 2007, 2012) $)^{12}$. Desde este enfoque, los primeros corresponden a las circunstancias sociales y condicionamientos situacionales en que adviene dicho discurso y, los segundos, a los significados, temas o contenidos vehiculados por el mismo. La siguiente figura explicita el instrumento de análisis construido desde la perspectiva semiolingüística (figura 01).

Figura 1 Categorías y códigos del enfoque semiolingüístico

\begin{tabular}{|c|c|c|c|}
\hline & Categoria & Códigos & Definiciones \\
\hline \multirow[t]{14}{*}{$\begin{array}{c}\text { Rasgos } \\
\text { contextuales }\end{array}$} & \multirow[t]{5}{*}{ Dominio polftico } & $\begin{array}{l}\text { Acción politica } \\
\text { gubernamental }\end{array}$ & $\begin{array}{l}\text { Prácticas de un gobierno juzgadas como } \\
\text { legítimas/ ilegítimas o legales/ilegales. }\end{array}$ \\
\hline & & $\begin{array}{l}\text { Acción política } \\
\text { ciudadana de } \\
\text { oposición }\end{array}$ & $\begin{array}{l}\text { Prácticas ciudadanas encaminadas a resistir } \\
\text { las acciones políticas de gobierno. }\end{array}$ \\
\hline & & Ideal político & $\begin{array}{l}\text { Proyecto político encaminado al bienestar } \\
\text { general. }\end{array}$ \\
\hline & & Relación política & $\begin{array}{l}\text { Correlaciones típicas que en el campo de la } \\
\text { política se establecen entre la instancia } \\
\text { política y la instancia ciudadana: abuso de } \\
\text { poder, opresión, discriminación. }\end{array}$ \\
\hline & & Valores políticos & $\begin{array}{l}\text { Representaciones socialmente compartidas } \\
\text { que organizan las acciones y las } \\
\text { evaluaciones. }\end{array}$ \\
\hline & Géneros discursivos & $\begin{array}{l}\text { Solapamiento de } \\
\text { géneros }\end{array}$ & $\begin{array}{l}\text { Cuando un género convocante se oculta bajo } \\
\text { los rasgos de un género convocado. }\end{array}$ \\
\hline & \multirow[t]{4}{*}{$\begin{array}{l}\text { Condicionamientos } \\
\text { situacionales }\end{array}$} & Participantes & $\begin{array}{l}\text { Locutor y destinatarios configurados en un } \\
\text { texto. }\end{array}$ \\
\hline & & Finalidad & $\begin{array}{l}\text { Alude a la orientación discursiva de la } \\
\text { comunicación, y se define en términos de } \\
\text { los objectivos discursivos perseguidos. }\end{array}$ \\
\hline & & Asunto temático & Es cl objeto de discurso. \\
\hline & & $\begin{array}{l}\text { Dispositivos } \\
\text { materiales }\end{array}$ & Soportes materiales de comunicación. \\
\hline & \multirow[t]{2}{*}{$\begin{array}{l}\text { Condicionamientos } \\
\text { discursivos }\end{array}$} & $\begin{array}{l}\text { Comportamientos } \\
\text { enunciativos }\end{array}$ & $\begin{array}{l}\text { Medios de expresión que dan cuenta de las } \\
\text { posiciones del hablante en sus actos } \\
\text { enunciativos. }\end{array}$ \\
\hline & & $\begin{array}{l}\text { Modos de } \\
\text { organización del } \\
\text { discurso }\end{array}$ & $\begin{array}{l}\text { Maneras de organizar el discurso en función } \\
\text { de la finalidad comunicativa pretendida. }\end{array}$ \\
\hline & \multirow{2}{*}{$\begin{array}{l}\text { Condicionamientos } \\
\text { formales }\end{array}$} & Superestructura & La organización esquemática del texto. \\
\hline & & Fraseología & Modos de expresión peculiares de un grupo. \\
\hline
\end{tabular}

Fuente: elaboración propia.

${ }^{12}$ La caracterización conceptual de esta perspectiva, Patrick Charaudeau la hace sobre todo en publicaciones de estos años. En las referencias bibliográficas estas fuentes son explicitadas. 


\section{Descripción referente a los rasgos situacionales}

El procedimiento aplicado para esta actividad es como sigue: primero se detalla el código y luego se acude a un enunciado auténtico para fundamentar lo reseñado. Se acude a la técnica del resaltado, pero cuando la situación lo amerita se recurre a una explicación adicional.

\section{Dominio político. Respecto a esta categoría se encontró:}

a) que en todos y cada uno de los textos que produjo cada organización social siempre las acciones gubernamentales fueron presentadas de manera negativa. Desde la teoría de la resistencia civil propuesta por Michel Randle, esta observación se puede explicar señalando que las producciones verbales que tales organizaciones produjeron también constituyeron una manera de hacer oposición política, pero una oposición mediante la modalidad resistencia discursiva:

Señor Presidente Uribe: usted utiliza la mala fe para gobernar, pues su discurso, como lo dijo el comentarista internacional Eric Toussaint, es francamente mentiroso, habla de paz y practica todo lo contrario, utilizando a veces al ejército y a grupos paramilitares para llevar a cabo su política de seguridad democrática; menciona la solidaridad y el respeto a los Derechos sociales y ordena a sus técnicos estudiar la manera de romper la solidaridad de los sindicatos, creando cooperativas de trabajo que privan a los trabajadores de sus conquistas sociales. (Texto Orivac).

b) Que los actos de lenguaje de las organizaciones que participaron en la MRSC estuvieron destinados a mostrar sus acciones de resistencia como acciones políticas legítimas y legales:

Reiteramos que como pueblos indígenas y ciudadanos colombianos estamos acudiendo a nuestro derecho a la protesta social y a manifestar nuestro desacuerdo frente a las políticas y leyes promovidas por el gobierno que atentan contra la vida y la integridad social y territorial." (Texto Aiwa).

Aseveran (...) que la Minga es política, para hacerle oposición al gobierno. Lo primero es falso, lo segundo es cierto y no es un delito. (Texto Tejido de comunicación). 
En este último enunciado, valga aclarar que el locutor al oponerse a la aseveración que tilda a la minga de política cae en una especie de autofagia, pues, parece ignorar que todo acto de oposición es de por sí una acción política. c) Que el ideal político de la MRSC se subsume en un proyecto político en el cual haya mejores condiciones de vida y una sociedad más equitativa; un país donde haya garantías para una vida, donde se respeten los derechos humanos colectivos e individuales:

Afirmamos nuestro compromiso con el bienestar de todos los pueblos, con la equidad la justicia social, y lo hacemos como pueblos ancestrales y originarios. (Texto ACIN)

Para que el país con dueños y sin pueblos se derrumbe, de modo que el país de los pueblos y sin dueños surja. (Texto Tejido de comunicación).

d) Relación política. Las correlaciones de fuerza entre la instancia política gubernamental y la instancia política de oposición fueron referidas por esta última en términos de represión, inequidad, injusticia social, abuso de poder, uso de la fuerza, imposición, estigmatización, autoritarismo, protesta y resistencia:

Todo esto es la punta del 'iceberg' ya que el gobierno maquilla magistralmente los proyectos de ley que propone al congreso para su aprobación, de tal manera que el pueblo no alcanza a comprender las desgracias que le acarrean estas modificaciones a la Carta Magna. (Texto Orivac).

Sin embargo, cuando nosotros retenemos y protegemos a un policía y lo entregamos sano y salvo, un Ministro nos llama terroristas. (Texto Minga de los pueblos).

Para que no nos sigan matando y despojando, salimos, bloqueamos vías, marchamos y vamos a seguirlo haciendo hasta cuando se respete nuestra palabra y se le dé curso a un diálogo que transforme en hechos esta realidad de miseria y horror por una de equilibrio, armonía y libertad. (Texto Minga de los pueblos).

e) Valores políticos. La verdad, la dignidad, la libertad, la vida, el diálogo franco y sincero, el equilibrio y la armonía, la honestidad, la verdad, respeto a la lucha legítima, la autonomía, el respeto por la vida del otro, la diversidad, el debate 
abierto, la protesta y la resistencia, la justicia social, la equidad aparecen como los valores más enfatizados:

la esclavitud no es una opción, sólo lo es la libertad.

Frente a la muerte, seguimos seguiremos proclamando y defendiendo la vida y la dignidad. (Texto Tejido de comunicación).

Somos pueblos de la palabra y el diálogo. Amamos y defendemos el diálogo. (Texto Minga de los pueblos).

\section{Género discursivo. Respecto a esta categoría se encontró:}

Que tres textos fueron rotulados como cartas, uno como comunicado de prensa y los restantes como noticias. Sin embargo, en todos ellos operó un solapamiento de subgéneros, pues se caracterizaron por cruzar características de dos subgéneros en un mismo texto. En esencia, en el género discurso político de resistencia, se solaparon rasgos de un género convocante con los de un género convocado: los subgéneros convocantes son el manifiesto, la proclama y la declaración, y los convocados la notica, el boletín de prensa, el comunicado de prensa y la carta.

Respecto a este código merecen breve explicación los subgéneros manifiesto, proclama y declaración. El primero, según Carlos Mangone y Jorge Warley, es literatura de combate, emergencia de una vanguardia, política, artística o social. Al tiempo que se da a conocer, enjuicia sin matices un estado de cosas presente; fingiendo describir, prescribe, aparentando enunciar, denuncia. Además, construye al otro como enemigo, en una guerra verbal donde dominan la refutación y la injuria ${ }^{13}$.

El segundo, es un discurso de carácter político en el que un sujeto, individual o colectivo, generalmente con autoridad, se dirige a otros para expresar una necesidad perentoria o para instarlos a hacer algo de manera inmediata. Y, el tercero responde a discursos públicos que implican una toma de posición respecto a un tema o punto de vista. En tanto que maneras públicas de fijar posicionamientos sobre determinados temas, muchas declaraciones prescriben acciones a seguir.

${ }^{13}$ Carlos Mangone y Jorge Warley, El manifiesto, un género entre el arte y la política (Buenos Aires: Editorial Biblos, 1994), 10. 
Condicionamientos situacionales. Respecto a esta categoría se observó que:

a) La identidad de los participantes tuvo que ver con dos tipos de sujetos: el locutor o voz responsable del texto y los destinatarios o sujetos de palabra configurados por el sujeto locutor. Respecto, a la voz responsable, siempre correspondió a un sujeto colectivo (la organización o asociación responsable de cada texto). En cuanto a los segundos, los más importantes fueron: el presidente Álvaro Uribe Vélez, miembros y organismos del gobierno Uribe, los medios de comunicación, los colombianos, organismos nacionales e internacionales defensores de los derechos humanos:

Colombianos, aunque el estado imponga su fuerza y acalle nuestras voces, aunque nos judicialicen tildándonos de terroristas (y quien mayor terrorista en Colombia que el propio estado), lean con cuidado y estudien nuestras manifestaciones y piensen que hablamos con la verdad. (Texto Orivac).

La mayoría de los congresistas, los que respaldan al Gobierno del Presidente Uribe, los que han aprobado las leyes que nos despojan de nuestros derechos y libertades, ocupan sus cargos con el respaldo de paramilitares y están vinculados a la parapolítica. Ni ellos, ni las leyes que han aprobado tienen legitimidad alguna. (Texto Minga de los Pueblos).

b) Finalidad. Entre los objetivos que hace saber el discurso político de resistencia de la MRSC se destacan: informar, persuadir, incitar, denunciar:

Las legítimas demandas se ignoran. El ejercicio de derechos y libertades se niegan, el territorio se entrega a las transnacionales, la guerra sucia asesina comuneros ylíderes, los medios engañan y promueven el terror yla manipulación. (Texto CRIC).

c) Asunto temático. El tema global que es tratado en este discurso político de resistencia son las medidas globalizadoras y neoliberales implantadas por el presidente Uribe y, de manera más específica, los 5 temas mencionados antes.

d) Dispositivo material. Las circunstancias materiales mediante las cuales es puesto en escena el discurso político de resistencia responden a una situación monolocutiva en la que el soporte de transmisión es de carácter virtual. Como se dijo, los textos fueron descargados de la página web de la Acin. 
Condicionamientos discursivos. De los dos comportamientos discursivos que se tomaron en cuenta, se encontró:

a) Que entre los modos enunciativos que permiten explicitar las diferentes posiciones e intenciones de los locutores, los tres tipos de actos locutivos ${ }^{14}$ de base (elocutivos, alocutivos y delocutivos) fueron movilizados de manera indistinta:

Cuando los pueblos nos sabemos esclavos, las cadenas estorban y desde ese momento la libertad se hace indispensable, impostergable, tan necesaria como el aire para respirar. (texto Tejido de comunicación).

Presidente, por ahora hable, siga hablando, sígale mintiendo al país y al mundo para que quede claro de una vez y para siempre que usted miente, ha mentido $y$ seguirá mintiendo. (Texto Tejido de comunicación).

El gobierno de Colombia con los empresarios, seguidos de cerca por las cámaras, los micrófonos y la gran prensa, corren vergonzosamente a montar un espectáculo de negociación y civilidad cargado como siempre de engaños y mentiras. (Texto Acin).

En el primer enunciado, la modalidad elocutiva es la del saber o la constatación; en el segundo, la modalidad alocutiva es la interpelación y, en el tercero, la modalidad delocutiva es la de la aserción.

b) Modos de organización del discurso. En virtud de que los modos de organización son procedimientos que consisten en utilizar categorías lingüísticas para ordenarlas en función de los objetivos del acto de comunicación, se encontró que los modos narrativo, descriptivo y argumentativo co-ocurren en cada uno de los textos del discurso político de resistencia. Respecto al modo argumentativo se observa que tal

${ }^{14}$ Patrick Charaudeau distingue tres tipos de comportamientos enunciativos: los actos alocutivos, los elocutivos y los delocutivos. Mediante los primeros, el locutor en su acto enunciativo implica al interlocutor, le impone el contenido de su discurso; mediante los segundos, en su acto de enunciación el locutor revela su propia posición en relación con lo que dice. Y mediante los terceros, el locutor deja que el discurso se imponga como si no tuviera un responsable. Patrick Charaudeau, Grammaire du sens et de léxpression (Paris: Éditions Hachette, 1992), 650 
discurso testimonió más una dimensión argumentativa que una intención argumentativa $^{15}$ :

Hieren más de 60 indígenas, la mayoría a bala. Asesinan a por lo menos dos civiles, maltratan comuneros y comuneras. Quemaron casas, cometieron actos de brutalidad incuestionable, destrozaron material médico y de atención en salud, destruyeron comida, han actuado como criminales bajo las órdenes del ejecutivo. (Texto Minga de los pueblos).

A este microrrelato, además de las secuencias narrativas y descriptivas empleadas, también le es inherente una dimensión argumentativa, pues, aunque como un todo no apunte deliberadamente a producir un efecto persuasivo, no obstante, las acciones descritas sí tienden a incidir en el pensamiento del destinatario prefigurado.

Condicionamientos formales. a) Salvo las tres cartas y el comunicado de prensa que explícitamente testimonian las características de estos subgéneros, los restantes textos evidencian la organización esquemática del subgénero 'noticia'. Sin embargo, en el nivel de la composición textual interna, los rasgos que dominan son los que caracterizan a los subgéneros manifiesto, proclama y declaración. En todos los textos que componen el corpus de estudio se evidencian rasgos de estas tipologías textuales.

b) Fraseología. Entre las unidades fraseológicas más utilizadas en los textos que constituyen el discurso político de resistencia de la movilización MRSC se observó el uso de locuciones alusivas tanto a la dominación como a la resistencia.

Obliga el régimen a los pueblos a levantarse en dignidad. Mañana, 12 de octubre, marcha la palabra de los pueblos convocando una conmoción en resistencia desde la conciencia. El terror ha puesto en marcha su maquinaria de represión y falsedad. Hagamos visibles las cadenas para quitárnoslas de encima. No habrá quien lave su sucia conciencia. Para que el país con dueños y sin pueblos se derrumbe de modo que el país de los pueblos y sin dueños surja. (Textos Tejido de comunicación).

${ }^{15}$ Desde el análisis argumentativo del discurso, Ruth Amossy distingue entre intención argumentativa y dimensión argumentativa. La primera hace referencia a aquellos discursos que explícitamente apuntan a actuar sobre una audiencia. La segunda alude a aquellos discursos que ejercen una influencia, pero sin tener en mira un acto deliberado de persuasión. Ruth Amossy. L'argumentation dans le discours (Paris, Éditions Nathan/Her, 2000), 25. 
Seguiremos caminando la palabra en busca de la verdad como único camino para construir la Democracia. (Texto CRIC).

Dispositivo comunicacional del contrato oposición política. El análisis de las instancias que constituyen el dispositivo contrato de comunicación oposición política permitió concluir:

a) Que la instancia ciudadana opositora estuvo representada por todas aquellas asociaciones y organizaciones que participaron en la movilización e hicieron minga discursiva;

b) Que la instancia gubernamental oponente aludió al presidente Álvaro Uribe Vélez o a aquellos otros actores políticos oficiales que hicieron parte de su gabinete.

c) Que la instancia de opinión la constituyeron aquellos destinatarios que fueron objetivo de influencia.

\section{Descripción referente a los rasgos de contenido:}

Ideología ${ }^{16}$ política de resistencia. En los textos que las distintas organizaciones produjeron, se movilizaron conocimientos específicos y creencias sociales que estas agrupaciones comparten. Estas creencias colectivas de manera evidente dieron testimonio de actitudes ${ }^{17}$ negativas tanto a los postulados de la globalización neoliberal como a las políticas y medidas gubernamentales puestas en marcha por el gobierno Uribe, que, según tales organizaciones, atentan contra sus planes de vida:

La conquista neoliberal, más cruenta y tecnificada que comenzó con la llegada de Europa, avanza con su afán insaciable y codicioso de acumulación.

El gobierno y las instituciones estatales permiten, favorecen y auspician las incursionesdegrandestransnacionalesqueacaparanen el mundolosminerales,

${ }^{16}$ El concepto de ideología tenido en cuenta fue tomado de Teun A. van Dijk, quien desde una teoría multidisciplinaria define las ideologías como sistemas básicos de creencias porque otras creencias más específicas dependen de ellas o se organizan a su alrededor. El concepto de ideología es un tipo de cognición social y, más específicamente, un conjunto de creencias básicas que fundamentan las representaciones sociales de un grupo. Teun A. van Dijk, Ideología y discurso (Barcelona, Editorial Ariel, 2003), 23-25.

${ }_{17}$ Teun A. van Dijk define las actitudes como opiniones sociales compartidas, admitidas con base en criterios evaluativos, esto es, fundamentados en normas y valores. Teun A. van Dijk, Discurso y poder (Barcelona, Editorial Gedisa, 2009), 273. 
las aguas la infraestructura, las tierras agrícolas. (Texto Ambientalistas en acción).

No somos ajenos a la política de guerra económica que ha implementado el gobierno agenciado por los EE. UU y las multinacionales; liderado por el señor Álvaro Uribe. (Texto Coordinación de jóvenes del Cauca).

En estos enunciados, las expresiones resaltadas dan cuenta de creencias evaluativas sociales que permiten inferir que la ideología en torno a la cual se cohesionan las organizaciones que participaron en la MRSC responde a una ideología antineoliberal.

Imaginarios sociodiscursivos. Una mirada de conjunto del discurso político de resistencia de esta movilización permite inferir que los enunciados empleados dejan entrever que en ellos se expresan representaciones que dan cuenta de los siguientes imaginarios socio- discursivos:

a) El imaginario de la agresión continua. Este imaginario es referido por enunciados que ponen de manifiesto actos agresivos de:

Naturaleza física

Que los crímenes de estado que se vienen cometiendo sean sujeto de acciones en derecho por parte de organismos internacionales. Que todas las víctimas sean atendidas y reparadas. (Texto Tejido de comunicación).

Naturaleza social

desesperar a los excluidos y explotados: cierre de espacios, negación de derechos $y$ libertades, persecución y señalamiento de líderes. (Texto Tejido de comunicación).

Naturaleza verbal

Un Ministro nos llama terroristas. Dice el gobierno que nos manipulan fuerzas oscuras, que las FARC nos infiltran. (Texto Minga de los pueblos).

b) El imaginario de la resistencia. Este imaginario es referido por enunciados que ponen de manifiesto los distintos actos de protesta emprendidos para confrontar los actos de agresión: 
Para que nos escuchen, para que no nos sigan matando y despojando salimos, bloqueamos vías, marchamos y vamos a seguirlo haciendo hasta que se respete nuestra palabra y se le dé curso a un diálogo que transforme en hechos esta realidad de miseria y horror por una de equilibrio, armonía y libertad. (Texto Minga de los pueblos).

c) El imaginario de la identidad colectiva. Este imaginario es sostenido por enunciados que fundamentalmente enfatizan en la categoría pertenencia, el hecho de ser pueblos originarios con unos valores propios:

Somos dignos. Tenemos un proceso histórico, planes de vida, territorio $y$ autonomía. (Texto Tejido de comunicación).

Somos pueblos de la palabra y el diálogo. Amamos y defendemos el diálogo. Lo hemos convertido en camino en nuestras asambleas y planes de vida. (Texto Minga de los pueblos).

Los indigenas se mantienen en defensa de la autonomía territorial, reclamando garantías de sus derechos históricos como pueblos originarios. (Texto CRIC).

d) El imaginario de la tradición. Este imaginario es sostenido por enunciados que fundamentalmente enfatizan en la conservación de valores fundadores que son amenazados por otros tipos de imaginarios:

Por el respeto a la vida, la autonomía, la identidad cultural y la defensa del territorio.

(Texto Awá).

Para el indio el pasado representa el futuro, $y$ si el indio olvida su historia empieza a morir culturalmente. (Texto Orivac)

Afirmamos que estamos ante el completo arrasamiento de nuestro tradicional modo de vivir, la sistemática expulsión de sus propias tierras y la violación de los fundamentos espirituales de nuestra cultura. (Texto Orivac).

e) El imaginario de la pervivencia. Este imaginario es sostenido por saberes de creencia que dan cuenta de todas aquellas acciones emprendidas para poder subsistir como pueblos ancestrales: 
Vamos a vivir porque nos cansamos para siempre del dolor, de la muerte y de la codicia de quienes nos roban la paz. (Texto Minga social y comunitaria).

Oponemos a los fusiles la palabra, a la violencia la palabra, al conformismo la resistencia civil. (Texto Acin)

Ante la amenaza inminente de muerte de la madre tierra, actuar en minga se convierte en un imperativo. (Texto Tejido de comunicación).

Como pueblos indígenas y ciudadanos colombianos estamos acudiendo a nuestro derecho a la protesta social y a manifestar nuestro desacuerdo frente a las políticas y leyes promovidas por el gobierno que atentan contra la vida $y$ la integridad social y territorial. (Texto Awá).

f) El imaginario de la dignidad. Este imaginario es sostenido por enunciados que permiten inferir que, para las organizaciones sociales que participaron en la movilización MRSC, la dignidad es un valor irrenunciable y uno de los ejes de su lucha:

Arriesgamos la vida por la libertad. Tenemos dignidad y reclamamos respeto. (Texto Acin).

Comparemos los hombres escudados de 'robocop', armados hasta los dientes con quienes con un bastón de mando se paran delante de ellos para defender con sus cuerpos la dignidad y el territorio. (Texto Tejido de comunicación).

Autoridades indígenas en resistencia, por la dignidad y el respeto a nuestros derechos fundamentales. (Texto Autoridades indígenas en resistencia).

g) El imaginario de la autonomía. Este imaginario es sostenido por enunciados que muestran que la autonomía no es sólo uno de los valores constituyentes de su identidad colectiva, sino también uno de los bastiones de su lucha:

El ritual de corrección fue realizado como un acto público y legítimo de la comunidad, en el marco de la autodeterminación de los pueblos indígenas reconocida internacional y constitucionalmente. (Texto CRIC).

Según la Constitución, las autoridades indígenas son autoridad estatal en sus resguardos. Y los resguardos no pueden ser allanados sin la previa aprobación indígena. (Texto Onic). 
Somos dignos. Tenemos un proceso histórico, planes de vida, territorios $y$ autonomía. (Texto Tejido de comunicación).

Marcos para la acción colectiva. Respecto a esta categoría se encontró:

a) Que en el marco de diagnóstico las creencias y conceptos expresados estuvieron destinados a dar cuenta de los innumerables actos padecidos por las organizaciones sociales, como consecuencia de la implementación de políticas y leyes promovidas por el gobierno del presidente Uribe siguiendo el modelo de desarrollo neoliberal:

\section{Con el gobierno de la Seguridad democrática solamente hay muerte, despojo} y mentiras. (Texto Tejido de comunicación).

Campesinos, indígenas, mujeres, estudiantes, entre otros se dieron cita en el territorio de Diálogo, Convivencia y Paz para traer su palabra de inconformidad, dolor, despojo, tristeza, sufrimiento, pero su palabra de propuesta ante la agresión constante que viven todos los pueblos en Colombia, víctimas del terror y la guerra y el sometimiento económico institucional. (Texto Tejido de comunicación).

b) Que en el marco de pronóstico, las creencias y conceptos expresados mostraron que entre las acciones emprendidas para solucionar las situaciones injustas se cuentan tanto las de carácter económico como las de naturaleza política:

Hacer minga para resistir y transformar el modelo económico, empezando porque no se apruebe el TLC ni lo demás que se le parezca para entregar el país y la vida a la codicia de algunos pocos. (Texto Tejido de comunicación).

En lo político, retomar la resistencia al modelo económico representado por los TLC y sus consecuencias, lograr la derogatoria de leyes que despojan a los pueblos y sectores de nuestros derechos y libertades, denunciar y actuar de manera conjunta y articulada frente a la seguridad democrática, el terror, la guerra y sus consecuencias. (Texto Tejido de comunicación).

c) Que en el marco de movilización los conceptos, valores, motivos y creencias movilizados para instar a la participación en la MRSC son muchos, pero todos relacionados con los cinco temas fundamentales que cruzan el discurso político de resistencia: 
El propio Estado que debe protegernos, nos amenaza y nos mata. (Texto Orivac).

Fuimos y seguimos siendo pueblos antes que grupos étnicos. (Texto Coordinación de autoridades indígenas en Colombia, regional Cauca).

Hoy están amenazadas nuestra vida comunitaria y colectiva, la posibilidad de prolongación de nuestra existencia como pueblos y culturas, y de hecho la diversidad cultural del país. (Texto Coordinación de autoridades indígenas en Colombia, regional Cauca).

Discurso antisistémico. Desde esta categoría los enunciados empleados estuvieron encaminados a dar cuenta tanto de las formas de dominación como de las formas de resistencia:

a) Formas de dominación. La descripción de estas formas involucró los siguientes mecanismos, relacionados todos ellos con el abuso del poder: represión, violación de derechos, legalización de leyes que los afectan, desconocimiento de acuerdos internacionales que los protegen y el irrespeto a valores fundamentales:

No vale la pena que piensen por nosotros, que nos sometan, que trabajemos para que otros se enriquezcan con nuestro esfuerzo. No es aceptable que tengamos hambre, que la tierra sea ajena y la estén matando, que las leyes se hagan para explotarnos y silenciarnos. (Texto Tejido de Comunicación).

Las legítimas demandas se ignoran. El ejercicio de derechos y libertades se niega, el territorio se entrega a trasnacionales, las leyes despojan, el Plan Colombia convierte territorios en teatro de operaciones, el gobierno respaldado por los EE. UU cierra el espacio para el conflicto político civilista y promueve la guerra para luego señalar como terroristas a quienes protestan. (Texto Tejido de Comunicación).

b) Formas de resistencia: la descripción de estas formas fue reportada mediante enunciados que dieron cuenta de las distintas acciones emprendidas para confrontar el patrón de poder dominante. Algunas de ellas son: las vías de hecho, la protesta pacífica, exigencias y el diálogo concertado:

Para que no nos sigan matando y despojando, salimos, bloqueamos vías, marchamos y vamos a seguirlo haciendo hasta cuando se respete nuestra palabra y se le dé curso a un diálogo que transforme en hechos esta realidad de 
miseria y horror por una de equilibrio, armonía y libertad. (Texto Minga de los pueblos).

Como pueblos indígenas, exigimos que la Declaración de las Naciones Unidas sobre los Derechos de los Pueblos Indígenas sea ratificada por el Estado colombiano como Ley de la República. (Texto Acin).

Esta Minga se propone establecer un camino sólido desde los pueblos para construir y poner en marcha una agenda de unidad desde la diversidad y el respeto, a partir de sentir y compartir el dolor para que se haga camino de vida y libertad. (Texto Acin).

Resultados: a partir de los resultados que arrojó la puesta en escena del instrumento de análisis, a continuación se presentan los hallazgos más significativos a la luz del objetivo pretendido

Rasgos contextuales. La construcción conceptual que ha sido denominada discurso político de resistencia de la movilización MRSC constituye un género discursivo, al que más exactamente se le ha dado el rótulo de género discursivo comunicación política de resistencia o contrato político de resistencia. Sin embargo, se hace la precisión de que sus características han sido determinadas a partir de la esfera de práctica social política, pues es sabido que los géneros también han sido abordados desde otros horizontes.

En primer lugar, lo anterior es importante porque los datos aportados permitieron sustentar que, tanto los actos materiales de protesta, como el discurso que le fue correlato respondieron a acciones políticas, en el sentido amplio que se le dio al concepto política ${ }^{18}$ En efecto, esta movilización correspondió a un evento situado en un contexto sociohistórico concreto, esto es, a un acontecimiento que tuvo lugar en el marco de un sistema político

${ }^{18}$ Esta concepción ampliada de política comprende los siguientes postulados: primero, la política y sus discursos se inscriben en la esfera pública y, al ser esto así, los actores políticos prototípicos no son los únicos que tienen voz, aunque sí un acceso preferencial a la palabra, es decir, que estos actores no son los únicos participantes en el campo de la comunicación política. En esta dirección Teun A. van Dijk señala que en dicho ámbito también deben ser incluidos aquellos otros actores políticos que, aunque no participan explícitamente de los aparatos institucionales en los que se desarrolla el juego del poder, no obstante, tienen como objetivo incidir en las relaciones de poder existentes (miembros de grupos de presión, grupos emergentes, activistas, disidentes, organizaciones, movimientos sociales, la opinión pública). Teun A. van Dijk, "Qué es análisis del discurso político?” en Análisis del discurso social y político, editado por Teun A. Van Dijk e Iván R. Mendizábal (Quito: Ediciones Abya-Yala, 1999), 29-102. 
específico, el tipo de democracia que se practica en Colombia. Esto permitió sostener que las relaciones de fuerza que se entablaron entre los actores oponentes como las de abuso de poder, opresión, por un lado, y las acciones ciudadanas legítimas de resistencia pacífica, por el otro, corresponden efectivamente a relaciones políticas. Esto, para decir que, desde la concepción amplia del concepto de política que se adoptó, se encuentra significativo que los únicos actores políticos no son sólo los políticos oficiales y sus respectivas acciones, incluyendo sus discursos. Desde esta concepción se contempla como representativo que también se pueden catalogar como actores políticos aquellos que hacen oposición mediante el método de la resistencia civil y sus distintas formas, incluyendo la resistencia discursiva.

En segundo lugar, los datos aportados de igual modo permiten mostrar como significativo que el discurso político de resistencia de la movilización MRSC es en esencia un género de discurso hibrido, pues de los 41 textos que constituyeron la muestra, 37 de ellos entrecruzaron rasgos del género información periodística prensa escrita con rasgos que caracterizan al género discurso político contestatario. Estos 37 textos dan testimonio de un fenómeno interesante. A nivel de la estructura esquemática o superestructura, todos estos textos adoptan la organización convencional de una noticia, pero cuando se hace el análisis de su contenido lo que se observa es que todos ellos ponen escena rasgos asociados a las tipologías textuales o subgéneros manifiesto, proclama y declaración.

Ahora, por cuanto desde esta perspectiva los géneros de discurso se definen a partir de tres niveles, el situacional, el discursivo y el formal, entonces para el primero lo significativo es que, por un lado, el asunto temático siempre giró en torno a las posturas globalizadoras y neoliberales desde las cuales el gobierno Uribe direccionó sus políticas públicas y, por el otro, la finalidad comunicativa fue expresada mediante los objetivos informar, persuadir, denunciar e incitar. Para el segundo, se emplearon indistintamente variadas modalidades de comportamientos enunciativos, pero igualmente secuencias prototípicas narrativas, descriptivas y argumentativas, las cuales, por lo general, confluyeron de manera conjunta en cada uno de los textos. Para el tercero, lo más representativo fue el despliegue de unidades léxicas o construcciones lingüísticas alusivas a la dominación y a la resistencia civil.

\section{Rasgos de contenido}

Respecto a este tipo de rasgos, de cada una de las cuatro categorías de análisis consideradas se desprendieron hallazgos significativos: 
En relación con el tipo saberes específicos de grupo, actitudes y valores ideológicos expresados en cada uno de los textos que constituyeron el discurso de la minga social y comunitaria, todas estas representaciones sociales compartidas guardaron correspondencia con principios y sistemas básicos de creencias relacionados con una ideología antineoliberal. Como bien se ha dicho, si hay un dominio que es ideológico, es el de la política; por ende, si se ha mostrado que el discurso de la movilización MRSC es un tipo de discurso que confronta a un modelo político e ideológico neoliberal, entonces lo que se infiere de ello es que tales valores, actitudes y conocimientos específicos de grupo encuentran su sustento en hecho de que los miembros de las organizaciones sociales que participaron en dicha movilización comparten una ideología de resistencia, una ideología que se opone a los axiomas del neoliberalismo. Desde luego, esto no significa que en este discurso no se movilizaron posicionamientos ideológicos de otra índole.

Imaginarios sociodiscursivos. De esta lista de imaginarios sociodiscursivos identificados en el discurso político de resistencia de la MRSC se encontró representativo que el imaginario de la identidad colectiva constituye el núcleo en torno al cual se cohesionaron las organizaciones participantes en la minga y sobre el que giraron los restantes imaginarios. En efecto, al ser descrito como el conjunto de representaciones que un grupo social reconoce y comparte como vínculos que los hacen pertenecientes a una determinada comunidad, tanto más si es un grupo social ideológico, se logra interpretar que imaginarios como el de la dignidad, la autonomía, la tradición, la pervivencia, la agresión continua y la resistencia apuntaron a develar, por un lado, la amenaza que sobre ella históricamente se ha cernido, y, por el otro, a poner de manifiesto las creencias sociales compartidas que han impulsado a dichas colectividades a defender a toda consta esta identidad colectiva.

Por esto, no en vano se ha propuesto que la relevancia de los imaginarios sociodiscursivos estriba en que al instituirse en normas de referencia que han sido naturalizadas por los grupos sociales, ellos, a su vez, son importantes porque también juegan el rol de justificaciones de sus acciones sociales.

Marcos de significación para la acción colectiva. Los marcos orientados a la acción colectiva están relacionados con los imaginarios sociodiscursivos. Ambos tienen en común que están asociados a procesos sociales, cognitivos y discursivos. Ambos son tipos de esquemas, pero lo que no se puede pasar por alto es que unos y otros son resultado de procesos sociales en los que 
la interacción y el discurso son fundamentales. Al igual que los imaginarios sociales, los marcos también son de naturaleza discursiva.

No obstante lo anterior, en el ámbito de los nuevos movimientos sociales, en el cual encaja perfectamente la movilización de MRSC, lo que resulta significativo es que un marco macro, subyacente a los tres tomados en consideración, es el de la acción discursiva colectiva. Esto explica que en esta investigación se haya empleado la expresión minga discursiva. Sin embargo, es en el marco de diagnóstico en el que se encuentra lo representativo, ya que fue el más enfatizado. Esto significa dos cosas: la primera, que los actos descritos, narrados y sustentados en la gran mayoría de los textos que constituyeron el corpus estuvieron destinados a dar cuenta de un estado padecido históricamente: la injusticia. Y, la segunda, que a tales actos injustos se les atribuyeron responsables. Para el caso concreto de las circunstancias en que tuvo lugar la MRSC, los actos injustos del momento fueron atribuidos al gobierno del presidente Álvaro Uribe y a sus políticas de Estado promovidas desde el modelo de desarrollo neoliberal.

Discurso antisistémico. El epíteto antisistémico nace en el marco de la perspectiva teórico- política conocida como colonialidad del poder y, sobre todo, para hacer referencia a aquellos movimientos que emprendieron olas de luchas y resistencias para desafiar y transformar el patrón de poder dominante en sus múltiples dimensiones. Sin embargo, la aplicación de esta categoría resultó significativa en la investigación realizada porque el calificativo de antisistémico no fue asociado a tal o cual movimiento social, sino por cuanto fue un concepto redefinido desde una perspectiva discursiva. Esto llevó a que desde el discurso que produjo la movilización MRSC se lograra identificar y explicar no solo las formas de poder empleadas por el poder dominante, sino también las formas de resistencia con las cuales aquellas fueron confrontadas.

\section{Conclusión}

Desde el momento en que se decidió emprender la empresa de analizar el discurso político de resistencia de la movilización MRSC desde el horizonte de los estudios del discurso, este objetivo general parecía indicar que a priori existía un objeto de saber con ese nombre. Sin embargo, esto no ha sido así. Por el contrario, lo que se ha logrado mostrar es que tal objeto es fruto de un esfuerzo de investigación previo que llevó a que se le construyera como tal. Con respecto al hecho de abordar este objeto de indagación desde una mirada discursiva ello se debe al deseo de brindar herramientas teóricas y 
metodológicas que posibiliten el emprendimiento de futuras investigaciones sobre un tema que, por lo menos en el contexto colombiano, aún permanece en estado incipiente.

En cuanto al objetivo específico que ha sido objeto de indagación en este artículo, las dos opciones escogidas para caracterizar el discurso político de resistencia de la movilización MRSC, sin duda aportan significativamente. Esto se sustenta diciendo que cuando una analista del discurso emprende la tarea de analizar cualquier tipo de texto, independientemente de la materialidad del sistema semiológico en la cual esté, tanto los rasgos contextuales como los rasgos de contenido son un buen punto de partida. En efecto, preguntarse por el dominio de práctica social, por el género discursivo, por los componentes de la situación de comunicación en la cual emerge el texto son herramientas que contribuyen, sea a la producción de un texto, sea a su comprensión. Pero detenerse en el significado de los enunciados que movilizan los participantes en una situación de intercambio es también muy importante, porque esto permite constatar que el individuo internaliza toda una gama de saberes diversos como efecto del proceso de socialización del sujeto mismo.

\section{Referencias bibliográficas}

\section{Fuentes secundarias}

Amossy, Ruth. Largumentation dans le discours. Paris: Nathan, 2003.

Castoriadis, Cornelius. L’institution imaginaire de la societé. Paris: Le Seuil, 1975.

Patrick Charaudeau. «Semiolingüística y comunicación». Núcleo-4, 29 (UCV, Caracas,1986): 1-19.

Charaudeau, Patrick. Grammaire du sens et de l'expression. Paris: Hachette, 1992.

Charaudeau, Patrick. Le discours politique. Les masques du pouvoir. Paris: Éditions Vuibert, 2005.

Charaudeau, Patrick. "Los géneros: una perspectiva socio-comunicativa”. En Los géneros discursivos desde múltiplesperspectivas: teorías y análisis, editado por Martha Shiro, Patrick Charaudeau y Luisa Granato, 19-44. Madrid: Iberoamericana, 2012.

Chihu, A. El análisis cultural de los movimientos sociales. Sociológica 15,42 (2000): 209-230.

Delgado, R. Los marcos de acción colectiva y sus implicaciones culturales en la construcción de la ciudadanía. Universitas Humanística, 64 (2002): 41-66.

Lao- Montes, Agustín. "Crisis de la civilización occidental capitalista y movimientos antisistémicos". Nexus, n. 9 (2011): 140-182.

Mangone, Carlos y Jorge Warley. El manifiesto, un género entre el arte y la política. Buenos Aires: Editorial Biblos, 1994. 
Minayo, Cecilia. El desafio del conocimiento. Investigación cualitativa en salud. Buenos Aires: Lugar, 2004.

Nieto, Jaime R. Resistencia. Capturas y fugas del poder. Bogotá: Ediciones Desde Abajo, 2008.

Randle, Michael. Resistencia civil.La ciudadanía entrelas arbitrariedadesdelos gobiernos. Barcelona: Paidós, 1998.

Sarmiento Anzola, Libardo. "Terrorismo neoliberal. Balance social desde los noventa”. Traza 3, n. ${ }^{\circ} 1$ (2002): 35-43.

Trujillo, Luisa F. “Resistencia civil indígena en el Cauca como forma de oposición”. En Renovadas formas de hacer oposición, compilado por Fredy Cante y Beatriz Franco, 201-222. Bogotá D. C: Editorial Universidad del Rosario, 2014.

van Dijk, Teun A. “¿Qué es análisis del discurso político?” En Análisis del discurso social y político, editado por Teun A. Van Dijk e Iván R. Mendizábal, 9-102. Quito: Ediciones Abya-Yala, 1999.

van Dijk, Teun A. Ideología y discurso. Barcelona: Editorial Ariel, 2003. van DIJK, Teun A. Discurso y poder. Barcelona: Editorial Gedisa, 2009. 
